\title{
Working with children with special needs in Finnish kindergartens: Professionals and/or specialists?
}

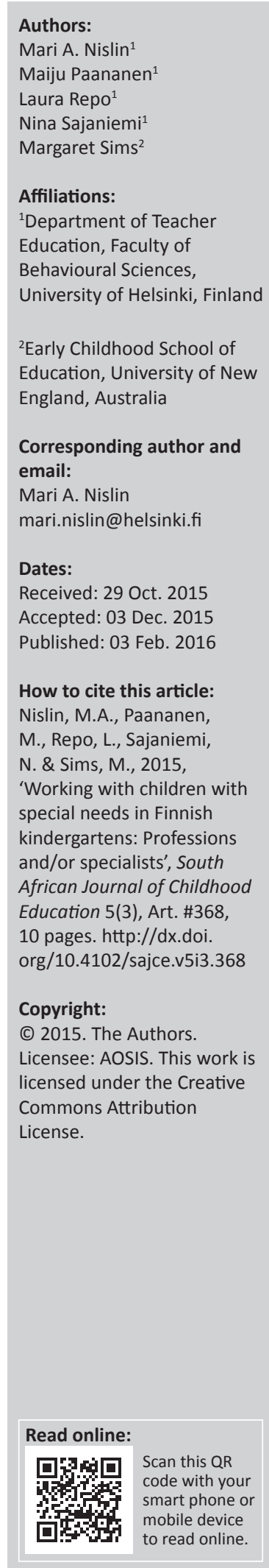

The aim is to investigate the links between job satisfaction of Finnish early childhood professionals (ECPs) and the appreciation they receive for their work, and how these are associated with their competence to work with children with diverse needs and backgrounds. Data was collected via nationwide online survey for practitioners $(n=885)$ working in Finnish kindergartens. The main findings show that ECPs experience their work as satisfactory and receive appreciation from colleagues, friends and the children's parents. It was also evident form the data that ECPs felt themselves to be incompetent to work with children with disabilities or children who had experienced trauma. This may reflect that more in-service training regarding these special education issues is needed. We argue that satisfaction, appreciation and competence, are key factors in the development of a strong professional identity, enhanced well-being at work and in other domains of life and particularly for high quality and inclusive early childhood education.

\section{Introduction: Professionalism in early childhood education}

There is ongoing international recognition of the importance of the early years in terms of long term adult wellbeing and national productivity (Heckman 2014; Sims 2013). The quality of programs for young children is therefore really important and there is substantial evidence to indicate that staff qualifications and working conditions have a major impact on quality and therefore on children's outcomes (Corr et al. 2015; Hall-Kenyon et al. 2014). Similarly, moves towards more integrative and inclusive early childhood education (ECE) settings requires selfreflection from early childhood professionals (ECPs) ${ }^{1}$ in relation to the extent they experience themselves to be skilful and competent to encounter children with special educational needs (SEN) or various backgrounds (e.g. children who are maltreated or neglected, children from LGBT $^{2}$ families). This requires ECPs to reflect on their perception of the balance between expert knowledge in special education versus expert knowledge in early childhood needed to deliver quality learning experiences to children with and without SEN and from various backgrounds.

As a result there are moves around the world to professionalize early childhood through increasing qualification requirements, and developing national curricula (Sims et al. 2015; Sims \& Pedey 2015; Sims \& Waniganayake 2015a, 2015b). Nevertheless, these moves are only one aspect in professionalization of ECE. Enhancing the status of early childhood workers has been seen as a political movement that brings with it significant risks to highly valued components of early childhood work. In the UK the side-lining of care from the early childhood discourse has resulted in ECPs feeling they have lost a very important element of their work (Chalke 2013; Sims 2014). In the Pacific, research suggests that the pursuit of a culturally appropriate early childhood curriculum runs counter to the pressures associated with a neoliberal professionalisation agenda (Sims \& Tausere-Tiko, in review). There is a growing body of literature concerning the issue of teacher professionalism and the construction of teachers' work and roles in the context of education reforms more widely (Apple 1986; Gewirtz et al. 2009; Sachs 2001). Much of this literature highlights the fact that conceptions of professionalism are fluid, multifaceted and powerful in their ability to influence on workers' roles (Gewirtz et al. 2009).

There are challenges in adapting the concept of professionalism in ECE settings. One key factor, we hypothesise, to reach the status of professional is to receive appreciation from the surrounding community and society. A key element of a strong professional identity is the validation received

1 In this study those who work in early childhood education and/or early childhood special education as educators will be referred to as early childhood professionals (ECPs).

2 LGBT family is a generally used term describing families with lesbian, gay, bi- or transsexual parents. 
for the work undertaken along with the knowledge and skills to undertake that work (Corr et al. 2015; Trede 2012). Work in ECE is not a highly valued profession and ECPs are not considered as important as primary teachers (Kaga, Bennett \& Moss 2010). One reason could be that workforce has been dominated by women and the work is considered work that should come naturally to women (as mothers) (Sims 2014). In addition, work in early childhood is poorly paid (Andrew \& Newman 2012) and conditions of work are often poor (Thorpe, Boyd \& Brownlee 2011). These factors all reflect a societal lack of appreciation that impact on early childhood workers perceptions of the meaningfulness of their work as well as their status as a professionals in the field.

Andrew and Newman (2012:242), state that 'As with other feminized fields, this caring labour involves a high level of emotional management, of the self and others, which remains undervaluedasaskillwithindiscourses of professionalization'. The emotionally loaded interpersonal work in required in ECE is not highly valued, creating significant risk for ECP stress, poor wellbeing and lack of satisfaction in their work. Poor overall wellbeing at work reflects negatively in other domains of life. It is well established that job satisfaction and well-being might be threatened if employees continuously feel inadequate and there are role conflicts in the working community (Hakanen 2009; Schaufeli, Bakker \& van Rhenen 2009). These notions resonate well with the growing body of literature in the field of ECE studies that has raised critique on the dominant construction of professionalism. The discourse of professionalism merging with the neoliberal idea of accountability has lead practitioners to be subjected to external evaluation (Osgood 2006). This top down quality assurance approach creates a discourse that influences how professional the staff feels; they judge themselves based on the discourse surrounding these policies (Bradbury 2012). While embracing these critical notions, we feel that instead of abandoning the discourse of professionalism there is a need to refinement of the concept. As a synthesis of these two bodies of literature we concluded that experienced appreciation and meaningfulness of work might be fundamental resources that enhance well-being.

There are number of studies focusing on the work-related well-being of professionals in the field of education (Bakker et al. 2007; Emery \& Vandenberg 2010; Fernet et al. 2012). In general, these studies position teaching as a highly stressful profession with multiple emotional and physical challenges; e.g. the need to manage children's challenging behaviour, hectic days, and poor physical working conditions. Nevertheless, there are still multiple positive characteristics that make early childhood teaching work meaningful and engaging for ECPs. Our previous studies have demonstrated that Finnish ECPs in regular and integrated special groups experience high levels of work engagement and their working resources were experienced by them as adequate. Positive attitudes towards their ECE work are reflected in better quality of pedagogical work and especially in more positive teamwork (Nislin et al. 2015a, 2015b). Basic elements of work such as caring for and teaching children are considered to enhance work satisfaction and joy (Rantala \& Määttä 2011) and overall, ECPs feel their work is meaningful and engaging (Estola, Erkkilä \& Syrjälä 2003). However we do not yet understand the ways in which ECPs' job satisfaction is linked with the value the world around them assigns their work (the appreciation they receive).

The ECE sector is organised differently in different countries around the world. Educational qualifications of staff may vary greatly, and the requirements are not uniform across different countries nor even across different states within countries. In many countries, a university degree in ECE is not required and there are jurisdictions where only minimal training is required to work with children in early childhood settings. This is of concern given many studies have demonstrated the importance of high quality ECE for children's learning and wellbeing and later outcomes (Vandell \& Wolfe 2000; Sylva et al. 2010). In addition to qualifications themselves, it is clear that a positive and supportive environment is one in which ECPs and children both experience wellbeing and participation (Roffey 2012). In establishing a professional identity for those who work in early childhood it is important to consider not just qualifications and curricula but job satisfaction and wellbeing (Canrinus et al. 2012). This is particularly interesting in the Finnish context because there are a range of people from different professional backgrounds working in early childhood and in kindergartens. In Finland ECE work is a multiprofessional collaboration (Nummenmaa \& Karila 2006) that involves early education teachers, special teachers, nursery nurses, and assistants with various educational backgrounds and pedagogical qualifications. The ECPs' qualifications reflect the ECPs' positions and responsibilities in the ECE teams, but the distribution of work within teams varies. National guidelines serve as a basis for the design of local curricula though municipalities are responsible for the implementation and steering of these services (Suhonen \& Nislin 2012). This means that there is some regional variation in organizing ECE and in the composition of the ECP teams, but for example in Helsinki metropolitan area at least one ECE teacher, responsible for pedagogy and planning of activities, is required in every group. When a child needs some additional support, an early childhood special education (ECSE) professional is also available.

The Finnish ECE system implements the principles of inclusion, whereby children with SEN are educated and placed in a kindergarten/preschool near home with children without SEN. Depending on the policy applicable in each municipality, kindergartens may contain integrated special groups (five children with SENs per group and seven children without special needs). Early special education can also be organized in segregated special groups if intensified support is needed although, according to the principles of inclusion, the perceived need for special education no longer requires a medical or psychological evaluation. Children with SEN represent a heterogeneous group with a number of 
competing definitions and classification systems which may differ between countries and municipalities (McManus, Carle \& Rapport 2014). Categorization of specific disabilities such as learning disabilities, language delays, behavioral problems or sensory and physical problems has been traditionally based on psychological and/or medical diagnostical classifications. The application of such categories has been justified because of the link between diagnosis and eligibility for support (Nilholm et al. 2013). In Finland, as well in other Nordic countries such as as Sweden, there has been a shift away from this diagnoses based approach in organizing the individual support in kindergartens and school environments (Nilholm et al. 2013; Pihlaja 2009). Classification and categorization might be harmful for children in terms of their identities and rights, as they are defined through specific traits and characteristics (Hanson et al. 2001). Thus in the Finnish context, the inclusion of children with SEN into kindergartens is complicated by the changes of perception related to eligibility criteria for support and this impacts on the role of ECPs working in groups inclusive of children with SEN.

At the core of pedagogical work with all children are interactions (between adults and children and between the various adults in the team). A key contributor to job satisfaction might be the extent to which ECPs consider themselves capable of successfully engaging in their pedagogical work with children. It is possible that, when working with children with SEN, ECPs may find this more challenging. Encountering children with various needs may challenge ECPs' competence and cause feelings of inadequacy. Additionally, children with various backgrounds force ECPs to reflect own attitudes and values if contrary with those held by the families. Personal private thoughts and subjective values should not have an impact on how the children and parents are treated and recognized. Traditionally, taking care of children with diverse educational needs has been a task of special teachers (Paju et al. 2015), and generally more segregated placements in organizing the teaching and care of children with SEN have been utilized. Nowadays, more inclusive practices are favoured, but there is uncertainty of the extent to which ECPs' qualifications and competence are adequate. Children with SEN in regular kindergarten groups may hence challenge ECPs' competence and if the responsibilities in teams are not well defined, this may have an impact on their satisfaction and quality of work. Given that they work in multiprofessional teams the varying different specialisations may contribute to difficulties in determining distribution of responsibilities particularly if tasks and duties are not bound to the educational qualification of the ECP (Onnismaa \& Kalliala 2010). Thus in the Finnish context the construction of an ECP professional identity may be rather more challenging than in other EC contexts and this may impact on job satisfaction (with the ultimate implication of impacting on quality which we are not investigating but about which we can speculate from the literature). In this study we investigate the links between job satisfaction of Finnish ECPs and their perception of the value others around them assign to their work (the appreciation they receive for their work), and how these are associated with their perceived competence to work with children with diverse needs and backgrounds.

\section{Research questions}

Our aim is to investigate ECPs' job satisfaction and the appreciation they receive from friends, colleagues and parents of the children for their work. Linked to this, we investigate to what extent appreciation is related to ECPs' work satisfaction and their working conditions. Further, our interest is to study how ECPs regard themselves to be competent in working with children identified as having SEN and/or who come from minority backgrounds, and how this perception of competence is associated with their job satisfaction.

The research questions of our study are:

1. What are ECPs' perceptions related to their job satisfaction and appreciation?

2. What is ECPs' perceived competence in working with children who have diverse needs and backgrounds?

3. How does ECP background characteristics (e.g. age, profession) impact on their perceptions of job satisfaction, appreciation and competence?

4. What are the relationships between ECP's job satisfaction, appreciation and competence in encountering children with various needs?

\section{Participants}

This study is part of an international comparative 'Professionalism in early childhood education' project that involves research groups from Finland (University of Helsinki), Australia (Sims 2014), Bhutan (Sims \& Pedey 2015), the Pacific (Sims \& Tausere-Tiko in review), South Korea (Park, Yang \& Sims 2015) and England (Oxford Brookes University - not yet published). The aim of the study is to investigate to what extent professionalism can be conceptualized in ECE and what are the benefits and possible challenges in this process. We received ethical approvals from the Ethical Committee at the University of New England, Australia. The informants were informed about the ethical issues and their anonymity was guaranteed. In this paper, we focus on the Finnish survey data that was collected via online survey in November-December 2014. The survey was delivered nationwide to practitioners and academics working in the field of ECE. Professions held by participants varied from early childhood teachers to researchers working in Universities, however the majority $(76 \%)$ of the respondents were working in kindergartens. ${ }^{3}$ With the help of the Associations of Kindergarten Teachers in Finland, ECE interest groups and the Finnish National Board of Education, who delivered the survey to their focus groups, we recruited 1159 participants. For this sub-study only those

\footnotetext{
3 This study was conducted within early childhood education (ECE) among children aged 0 to 6 . In Finland ECE consists of kindergarten (children aged 0 to 5 ) and aged 0 to 6 . In Finland ECE consists of kindergarten (children aged 0 to 5 ) and
preprimary education (children aged six). To encompass all the age groups, we will preprimary education (children aged six). To encompass all the age g
use the term kindergarten to cover the ECE for children aged 0 to six.
} 
TABLE 1: Descriptive statistics of ECP's background characteristics.

\begin{tabular}{|c|c|c|c|}
\hline Variable & Characteristics & $\mathbf{n}$ & $\%$ \\
\hline \multicolumn{4}{|c|}{ Profession } \\
\hline & ECE teacher & 741 & 83.7 \\
\hline & ECE special teacher & 68 & 7.7 \\
\hline & Nurse & 76 & 8.6 \\
\hline & Total & 885 & 100 \\
\hline \multicolumn{4}{|c|}{ Period of employment } \\
\hline & $<5$ & 173 & 19.5 \\
\hline & $5-15$ & 258 & 29.2 \\
\hline & $>15$ & 454 & 51.3 \\
\hline & Total & 885 & 100 \\
\hline \multicolumn{4}{|c|}{ Educational level } \\
\hline & Bachelor/master in ECE & 576 & 72.4 \\
\hline & Bachelor/master in ECSE & 62 & 7.8 \\
\hline & Bachelor/master (not ECE) & 27 & 3.4 \\
\hline & Bachelor (polytechnic) & 121 & 15.2 \\
\hline & Basic level & 10 & 1.3 \\
\hline & Total & 796 & 100 \\
\hline \multicolumn{4}{|l|}{ Age } \\
\hline & $<35$ & 231 & 26.1 \\
\hline & $35-45$ & 230 & 26 \\
\hline & $45-55$ & 275 & 31.1 \\
\hline & $>55$ & 149 & 16.8 \\
\hline & Total & 885 & 100 \\
\hline
\end{tabular}

participants who were working in kindergartens $(n=885)$ were selected.

There were 861 female (97.3\%) and 21 (2.4\%) male participants in the study. Three participants $(0.3 \%)$ did not want to define their gender. The descriptive statistics of the informants are presented in the Table 1. Participants were in general well educated, and over $90 \%$ of them held a university or polytechnic based bachelor degree. Most of the ECPs had a long career in ECE with over 15 years of employment.

\section{Measures}

We collected data with an online survey and in this paper we utilize items from the survey concerning job satisfaction and the appreciation ECPs experience at work, their evaluation of their competence in working with children with SEN and/or various backgrounds, and their background characteristics (e.g. age, profession, educational level, period of employment). The questions in the survey related to job satisfaction survey consisted of 13 items covering the following themes:

- Appreciation, (e.g. 'My friends appreciate the work I do', 'The colleagues appreciate $\mathrm{me}^{\prime}$; 'I receive appreciation and confidence from parents of the children I work with'),

- Stressfulness of work ('My working days are busy and hectic'; 'I do not recover easily from the job strain'.)

- Control over own work ('I feel I master my own work'; 'Most of the time, I enjoy to come to work')

- Working environment (e.g. 'I am satisfied with my physical working environment'; 'The work environment is aesthetical and appropriate'.)

- Social relationships (e.g. 'I feel I am an important member in my working community'; 'I solve easily possible conflicts with my colleagues'; 'I have warm and positive relationship with the children I work with')
Questions were answered on a 6-point Likert scale, so that the informants assessed their opinions from 1 (totally agree) to 6 (totally disagree). The overall reliability of the job satisfaction section of the survey was calculated with Cronbach's alpha and showed moderate internal consistency (0.75).

Further, we asked ECPs to assess their perceived competence in working with children with SEN. In the survey we included specific types of SEN and various backgrounds as below:

1. children with disabilities

2. children who had experienced trauma

3. children with a minority religious family background

4. children from LGBT families

5. children with parents abusing alcohol and/or drugs

6. children with serious illnesses

Participants were asked to identify if they felt competent to work with children from each of the groups identified and could answer yes/no. Answers were grouped into $1=$ competent and 2 = incompetent.

\section{Analysis}

The data was analysed by using IBM SPSS 22 Software for windows. To answer research questions 1 and 2 we obtained descriptive statistics (means, standard deviations) for workrelated satisfaction and appreciation to describe the data. Additionally, descriptive statistics for ECPs competence items were calculated.

To respond to question 3, we compared the differences between different occupational groups by using analysis of variance (ANOVA) with Bonferroni corrections, and in the case of dichotomous variables, Chi-square tests were used. In addition, age and period of employment were used as grouping variables in comparisons. The groups were the same as presented in Table 1. Further, to detect (question 4) if there were associations between job satisfaction, appreciation and competence, we used the Pearson's product-moment correlation coefficients.

\section{Results}

\section{ECPs' satisfaction with their ECE work}

First we obtained descriptive statistics for job satisfaction and appreciation that are presented in Table 2. On average, ECPs experienced positive job satisfaction. They felt enjoyment in their work $(M=1.9, \mathrm{SD}=0.80)$, and felt they had control of their own work $(M=1.9, \mathrm{SD}=0.85)$. In addition, they felt they had good relationships with the children with whom they worked $(M=1.4, \mathrm{SD}=0.62)$. They were less positive about work overload $(M=4.8, \mathrm{SD}=1.0)$ and their ability to solve conflicts with their colleagues $(M=3.5, \mathrm{SD}=1.1)$. They reported minimal ability to recover from the job strain $(M=$ 3.0, $\mathrm{SD}=1.2$ ). We conducted multiple ANOVAs to compare differences between teachers, special teachers and nurses in job satisfaction, but no variation was found. 
TABLE 2: ECPs' experienced job satisfaction and appreciation and pairwise comparisons according to the background characteristics.

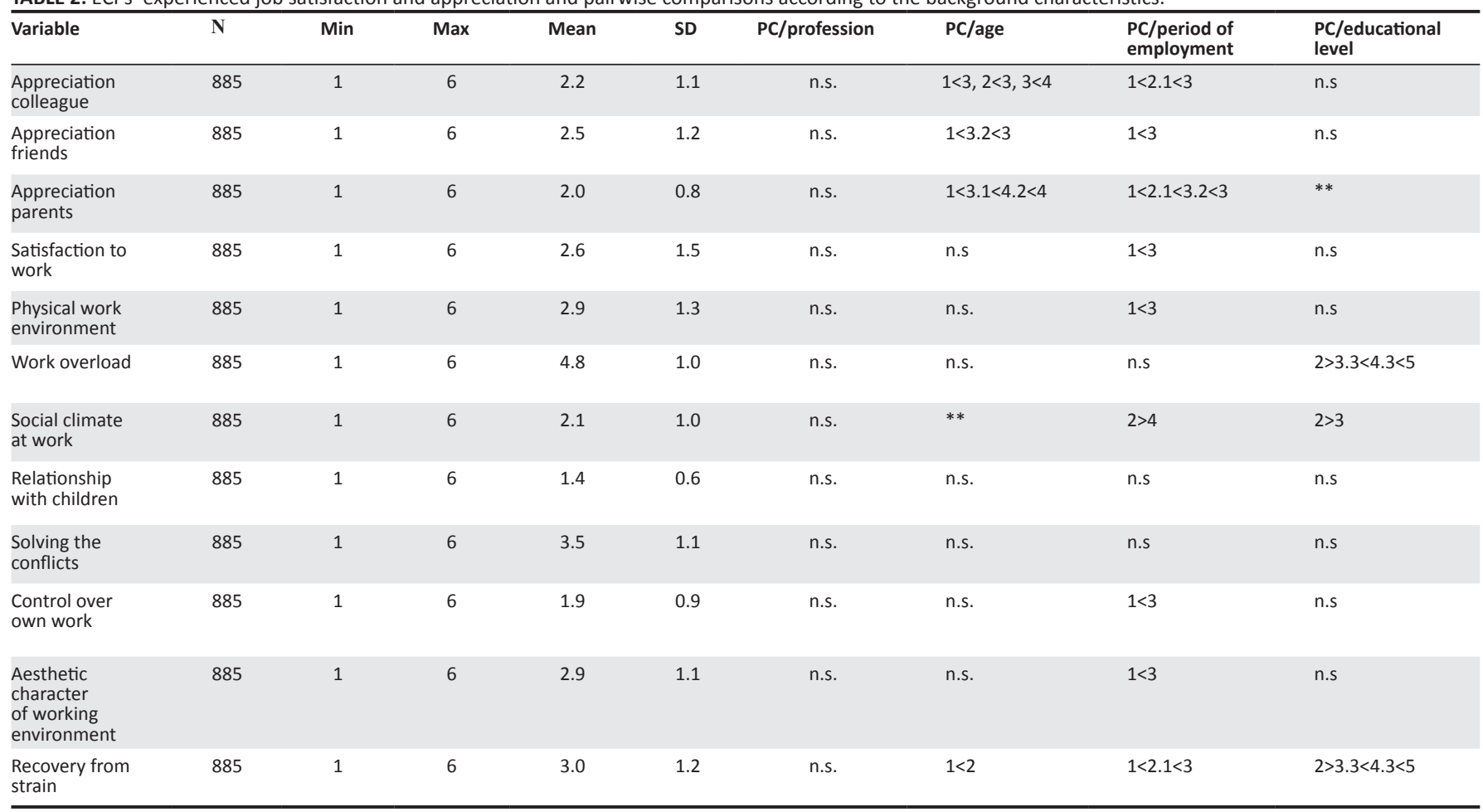

Sources: *Pairwise comparisons/PC (ANOVA) were conducted between teachers, special teachers and nurses with the significance level of $\mathrm{p}<0.05 ; * *$ significant difference between the groups was not found in Bonferroni post-hoc tests.

Nevertheless, we found differences in experienced job satisfaction between ECPs grouped according to their age, the period of employment in the field of ECE and their educational level. Older ECPs reported they experienced a more positive social climate at work and they were more likely to feel they were important members of their working community than younger ECPs $[F(3)=2.8, p=0.41]$. In addition, ECPs at the age of 35-45 years recovered more easily from work-related strain than the youngest ECPs $[F(3)=4.5, p=0.004]$. ECPs with a degree in special education reported a more positive social climate at work than those with a bachelor degree from a polytechnic institution $[F(4)=3.7, p=0.005]$. ECPs with no bachelor/master degree in ECE reported feeling a more burdensome work overload and more hectic working days than did those who had a degree in early childhood special education (ECSE), a bachelor degree from a polytechnic or basic level education $[F(4)=3.7, p=0.005]$. The period of employment was linked to experienced job satisfaction. More experienced ECPs were more satisfied to their work $[F(2)=3.4$, $p=0.034]$, recovered from strain easier $[F(2)=6.9, p=0.001]$ and experienced more control over their own work $[F(2)=4.4, p=$ $0.011]$ than those less experienced. Furthermore, they regarded their physical environment as more likely to be adequate $[F(2)=4.5, p=0.011]$ and more aesthetic $[F(2)=4.9, p=0.007]$. The results for these pairwise comparisons are presented in Table 2 (please see columns PC/profession, PC/age, PC/ period of employment and $\mathrm{PC} /$ educational level).

\section{Experienced appreciation among ECPs}

In general, ECPs were satisfied with their work in ECE and they felt they received appreciation from their friends, colleagues and children's parents (see Table 2). Teachers, special teachers and nurses did not differ in the levels of appreciation they received, nor were there differences between ECPs with different levels of education. However there were some associations between ECPs' age and period of employment and appreciation variables. The length of employment was correlated with the experienced appreciation from colleagues $(r=-0.14, p<0.01)$, parents $(r=$ $-0.16, p<0.01)$ and friends $(r=0.137, p<0.01)$, so that longer the ECP had been working in the field of ECE, the more he/ she felt valued and appreciated. We conducted ANOVAs with Bonferroni correction to test which groups differed the most, and a major difference was found between ECPs with the shortest working experience and those with over 15 years in the field. Similarly, ECPs' age correlated with the levels of appreciation from colleagues $(r=-0.10, p=0.002)$, parents $(r=-0.22, p<0.001)$ and friends $(r=0.12, p<0.01)$ : older ECPs experienced more appreciation compared to younger colleagues. Educational level was related to appreciation, with the more qualified ECPs with higher levels of education reporting they experienced more appreciation from parents $(r=-0.95, p<0.01)$.

\section{ECPs' competence in working with children with SEN and/or diverse backgrounds}

The results of the ECPs' competence in working with children with various needs and backgrounds are presented in Table 3. Results indicate that ECPs experience the most challenges working with children with severe disabilities and those with who have experienced traumas. They felt the most competent working with children from LGBT 
TABLE 3: ECPs' competence in encountering children with SEN and/or various backgrounds.

\begin{tabular}{|c|c|c|c|c|c|c|c|c|}
\hline \multirow[t]{2}{*}{ Child's background } & \multirow{2}{*}{$\begin{array}{l}\text { Professional } \\
\text { teacher }\end{array}$} & \multirow[t]{2}{*}{ Special teacher } & \multirow[t]{2}{*}{ Nurse } & \multirow[t]{2}{*}{ Total } & \multicolumn{4}{|c|}{ Pairwise comparions } \\
\hline & & & & & 1) & 2) & 3) & 4) \\
\hline Child with disabilities & - & - & - & - & - & - & - & - \\
\hline Competent & 243 & 45 & 29 & 317 & - & - & - & - \\
\hline \multirow[t]{2}{*}{ Incompetent } & 498 & 23 & 47 & 568 & - & - & - & - \\
\hline & - & - & - & - & $2>1.2>3$ & n.s. & n.s. & $1<2.2>3.2>4$ \\
\hline Child with traumas & - & - & - & - & - & - & - & - \\
\hline \multirow[t]{2}{*}{ Incompetent } & 465 & 36 & 43 & 544 & - & - & - & - \\
\hline & - & - & - & - & n.s. & n.s. & n.s. & $* *$ \\
\hline $\begin{array}{l}\text { Child with religious } \\
\text { family }\end{array}$ & - & - & - & - & - & - & - & - \\
\hline Competent & 583 & 53 & 53 & 689 & - & - & - & - \\
\hline \multirow[t]{2}{*}{ Incompetent } & 158 & 15 & 23 & 196 & - & - & - & - \\
\hline & - & - & - & - & n.s. & n.s. & n.s. & $* *$ \\
\hline Competent & 668 & 64 & 74 & 806 & - & - & - & - \\
\hline \multirow[t]{2}{*}{ Incompetent } & 73 & 2 & 2 & 79 & - & - & - & - \\
\hline & - & - & - & - & n.s. & n.s. & n.s. & $* *$ \\
\hline $\begin{array}{l}\text { Child with parents } \\
\text { abusing alcohol/ } \\
\text { drugs }\end{array}$ & - & - & - & - & - & - & - & - \\
\hline Competent & 463 & 38 & 47 & 548 & - & - & - & - \\
\hline \multirow[t]{2}{*}{ Incompetent } & 278 & 30 & 29 & 337 & - & - & - & - \\
\hline & - & - & - & - & n.s. & n.s. & n.s. & $1<4.2<4$ \\
\hline $\begin{array}{l}\text { Child with serious } \\
\text { illness(es) }\end{array}$ & - & - & - & - & - & - & - & - \\
\hline Competent & 343 & 40 & 40 & 423 & - & - & - & - \\
\hline \multirow[t]{2}{*}{ Incompetent } & 398 & 28 & 36 & 462 & - & - & - & - \\
\hline & - & - & - & - & n.s. & n.s. & n.s. & $1<2.1<4$ \\
\hline
\end{tabular}

Sources: *Pairwise comparisons/PC (ANOVA) were conducted between teachers, special teachers and nurses with the significance level of $\mathrm{p}<0.05 ; * *$ significant difference between the groups was not found in Bonferroni post-hoc tests.

families and families with minority religious backgrounds. The different professional groups differed only in their perceived competence in working with children with severe disabilities $\left[\chi^{2}(2)=30.31, p<0.001\right]$ : teachers trained in special education felt more competent in comparison to other teachers $(p<0.001)$ and nurses $(p=0.001)$. Younger ECPs were more at ease with children with LGBT family background $\left[\chi^{2}(5)=16.31, p<001\right]$ than older ECPs. ECPs did not differ in any other dimension according to their age. Interestingly, when looking at comparisons between the groups based on the educational level (please, see Table 1), it can be seen that the groups differed in all dimensions except in their perceived competence working with children from LGBT families $(p=0.64)$. After investigating which groups differed most, the difference was significant only in dimensions of 'child with disabilities', 'child with parents abusing alcohol/drugs' and 'child with serious illness(es)' as presented in Table 3. ECPs with qualifications in special education felt more competent in working with children with severe disabilities than other ECPs. In contrast ECPs with a bachelor degree in EC from a polytechnic institution felt more competent working with children who had parents experiencing alcohol abuse and with children who were seriously ill than ECPs with other qualifications.

\section{Associations between job satisfaction, appreciation and perceived competence working with the children who have diverse needs and backgrounds}

Items related to appreciation at work were strongly correlated with the other job satisfaction variables, and the results from the correlation analyses are presented in the Table 4. The results suggest that there are links between the ECPs' experienced job satisfaction and the appreciation they receive from their colleagues, friends and children's parents. The more the ECPs experienced appreciation the more they were satisfied with their work and working conditions. They felt part of the working community and capable to solve conflicts they encountered with colleagues. Appreciated ECPs were happy to come to work daily, and they felt that they were more able to easily recover from stress. ECPs who felt valued felt more positive about their physical or aesthetical working environment.

Finally, our aim was to explore to what extent ECPs' perceived competence with children who had various needs is related to their perceived appreciation and satisfaction at work. Results from these correlational analyses are presented in Table 4. Results suggest that appreciation from friends and 


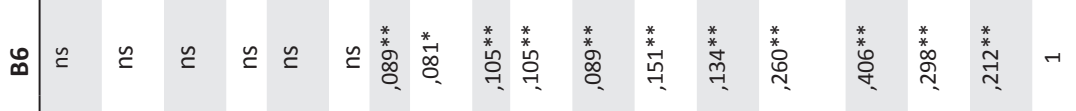

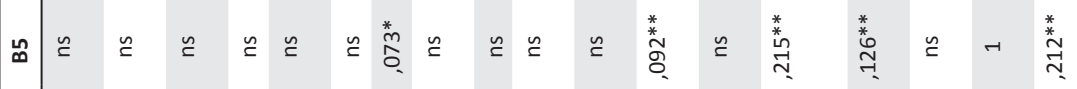

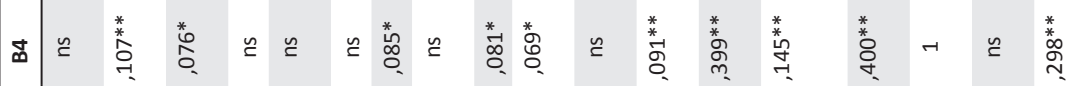

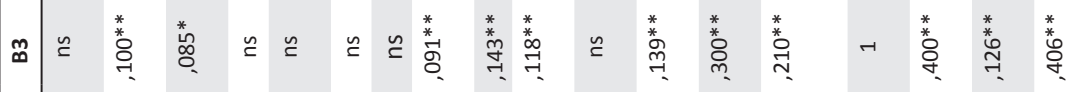

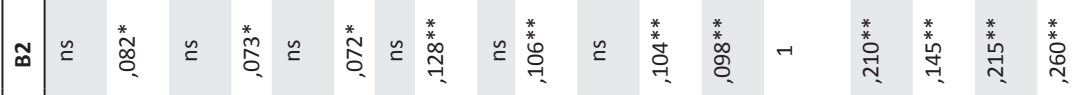

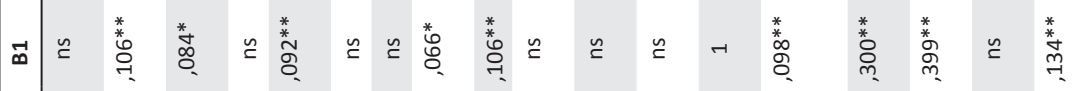

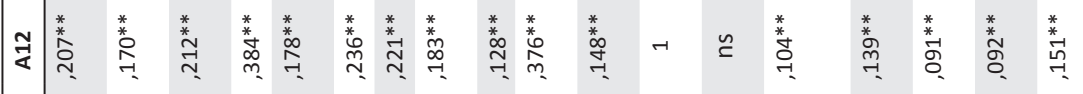

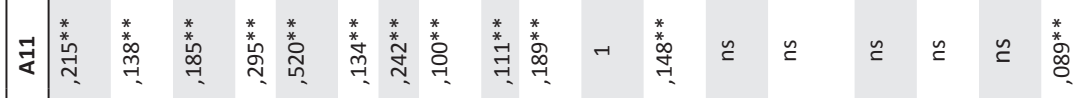

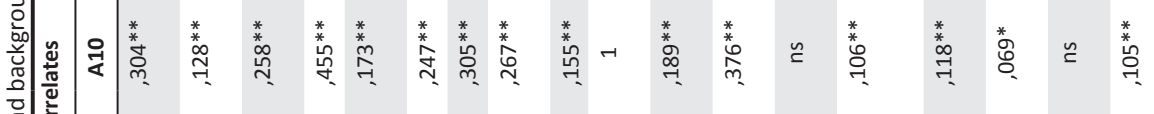

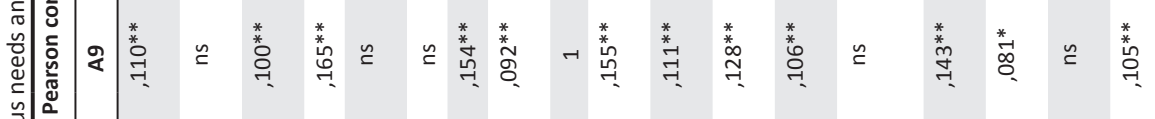
舟

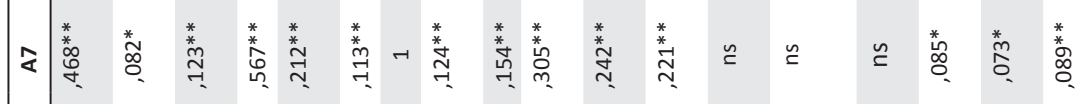
\&藮 凹

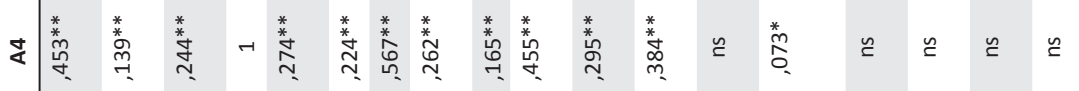

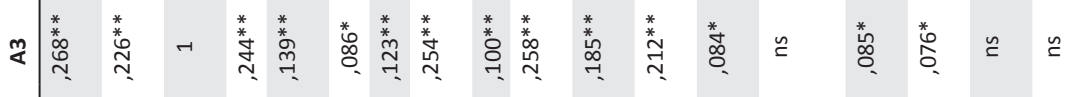

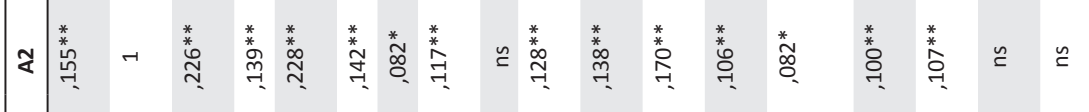

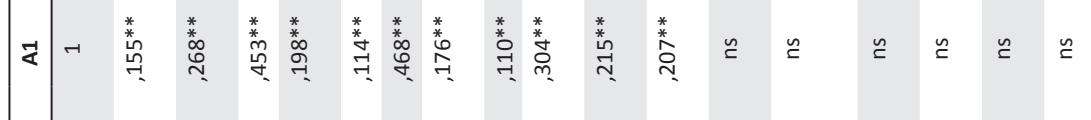

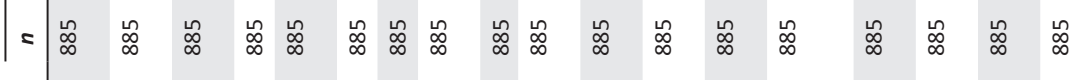

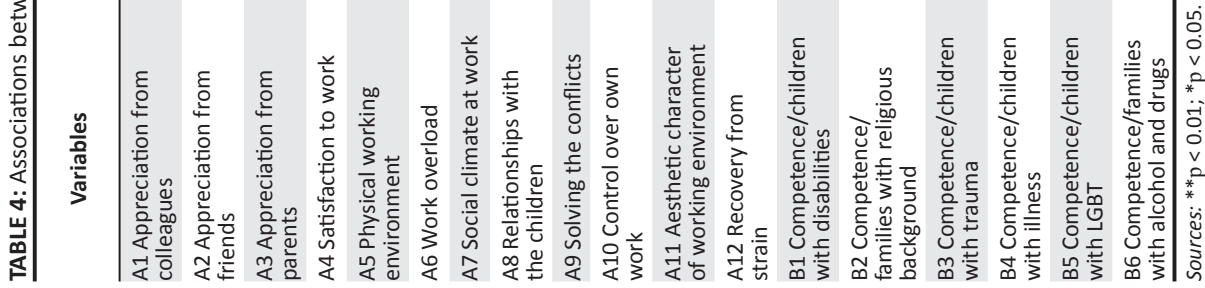


children's parents has a positive association with experienced competence in working with children with diverse needs. There were no correlations between competence variables and appreciation from colleagues. The perceived social climate at work (meaning that the ECP feels him/herself to be part of the working community and also that she/he has a positive relationship with children in the group) correlates positively with better perceived competence in working with children. Thus it appears that job satisfaction, appreciation and perceived competence are positively linked.

\section{Conclusions}

This study offers important viewpoints on ECPs' job satisfaction and appreciation and hence adds to existing literature regarding the professionalism and development of professional identity in the field of ECE. Additionally, our findings expose ECPs' experiences about their competence in encountering children with diverse needs and backgrounds. We argue that these elements, satisfaction, appreciation and competence, are key factors in the development of strong professional identity, enhanced well-being at work and in other domains of life and in particular for high quality and inclusive ECE.

These results from our present study support previous findings that ECPs generally regard their work as positive, enjoyable and engaging (Nislin et al. 2015b; Rantala \& Määttä 2011), and experience their work as autonomous (Nislin et al. 2015a). ECPs felt they had control over own work; they felt they had mastered their job and had freedom to decide the content of their work. This is important given that a number of studies have demonstrated that autonomy is one key factor that positively boosts job satisfaction and enhances work engagement (Hakanen 2009; Schaufeli \& Bakker 2014). In addition, ECPs assessed their relationships with the children to be good, and overall this was associated with their self-assessed competence in working with children with various needs. Similarly, ECPs' experiences regarding the social climate at work were linked to their perceived better competence with the children. This suggests that competence is socially influenced and given ECE work is highly interpersonal by nature, this is understandable.

However, ECPs across the board did not report high levels of job satisfaction, and there were some perceptions of work overload and strain. Even though these were on average moderate they should be taken seriously, as constant problems with recovery from job strain and work overload may, if prolonged, lead to many health problems (Hakanen 2009; Schaufeli et al. 2009). It is suggested, that coping problems at work are not private issues of individual workers, because these problems influence other workers and finally children. In particular positive workrelated emotions tend to be contagious as do negative attitudes (Perhoniemi \& Hakanen 2013).
It was not surprising that workers with longer experience felt more competent and appreciated. With a long experience in the field of ECE ECPs might be more prepared to solve conflicts and encounter challenges at work, and their professional identity builds up over their years of work in ECE. We are convinced that perceived appreciation is not just something externally given; rather is acquired and learnt in the course of working life. As Fagley and Adler (2012) argue it is not a static state or inherent unchangeable character; instead, appreciation can be taught and learnt. In this sense, it is important to realize that ECPs are not passive actors who wait to be appreciated and valued by their surrounding community; instead they may impact themselves on their perceived appreciation. An experience of being appreciated in their work is internal process that requires self-pride and advocacy aimed at raising awareness of the importance of ECE. This is not only the task of individual ECPs but something for which the whole working community is responsible. All in all, in the Finnish context, ECPs were generally more positive about their appreciation than the previous literature (e.g. Andrew \& Newman 2012; Kaga et al. 2010) may suggest.

ECPs were confident working with children from LGBT families or with minority religious backgrounds. This might also be because the needs of LGBT families or children with minority religious backgrounds are not identified by them as different from those of children from majority family or religious backgrounds. Confidence in encountering children with various needs and backgrounds could be one factor that enhances experienced job satisfaction. There were associations between job satisfaction variables and competence indicating that more positive attitudes towards the work is linked with better competence in encounters with children and families.

It is important to note that this data is based on selfperceptions and there has not been any external review of ECE practice in these areas in Finland. National level discourses institutionalised, for example, in assessment policies, have an impact on how professional the staff feels; they judge themselves on the basis on the definitions of success inherent in assessment policy (Bradbury 2012). The lack of external benchmarking in Finland may have created a false sense of competence among ECPs. Thus, our results in Finnish context resonate well with earlier examinations that link assessment policies with experiences of competence.

However, the lack of external benchmarking could equally create unrealistic expectations of performance. A somewhat alarming finding was that so many ECPs felt themselves to be incompetent working with children with disabilities or children who had experienced trauma. This may be a sign that more in-service training regarding these special education issues is needed, but it may also reflect the traditional distribution of ECPs roles and responsibilities in kindergartens in Finland. There is a lack of clarity between the different professional disciplines working in ECE: ie educational pedagogues, special needs educators and nurses 
(Onnismaa \& Kalliala 2010). Clearer division of responsibilities among ECPs accompanied with proper training concerning developing sensitive relationships to children could help ECPs navigate within different expectations and increase their experienced competence and job satisfaction.

There are some limitations in this study that should be taken into consideration. The data for this present study was gained from a wider survey study, and the questionnaire utilized in investigating job satisfaction and appreciation was not a standardized instrument. There are multiple valid instruments for investigating more in depth the work-related satisfaction and working conditions but these were not appropriate to use within the limitations of the study. Regardless the limitations, we believe that the questionnaire used produced valuable information, and more importantly the associations between the variables in question. Furthermore, it is important to note that our survey measured perceived competence rather than competence per se. This increases the likelihood that length of work experience may link to ECPs ability to navigate between different expectations, work distribution and professional identities. Due to these limitations there is still room for more nuanced measurements and analysis to strengthen these results. This is left for later inquiries.

At the beginning of this paper we suggested that the ECPs' role has social, cultural, educational and political significance. What seems certain is that practitioners working in the early years needs to be regarded as critical professionals who are able to formulate their professional identities and determine the content of their work based on their own expertise. However, to be able to do that they need tools for organizing the distribution of work and addressing the needs of children from various backgrounds.

\section{Competing interests}

The authors declare that they have no financial or personal relationships which may have inappropriately influenced them in writing this article.

\section{Authors' contributions}

M.A.N. (University of Helsinki), M.P. (University of Helsinki), L.P. (University of Helsinki), N.S. (University of Helsinki) and M.S. (University of New England) contributed equally to the writing of this article.

\section{References}

Andrew, Y. \& Newman, B., 2012, 'The value of childcare: Class, gender and caring labour', Contemporary Issues in Early Childhood 13(3), 242-247.

Apple, M.W., 1986, Teachers and texts: A political economy of class and gender relations in education, Routledge, New York.

Bakker, A.B., Demerouti, E., Hakanen, J.J. \& Xanthopoulou, D., 2007, 'Job resources boost work engagement, particularly when job demands are high', Journal of Educational Psychology 99(2), 274-284.

Bradbury, A., 2012, “I feel absolutely incompetent": Professionalism policy and early childhood teachers', Contemporary Issues in Early Childhood 13(3), 175-186.
Canrinus, E., Helms-Lorenz, M., Beijaard, D., Buitink, J. \& Hofman, W., 2012, 'Selfefficacy, job satisfaction, motivation and commitment, exploring the relationships between indicators of teachers' professional identity', European Journal of Psychology of Education 27, 115-132.

Chalke, J., 2013, 'Will the early years professional please stand up? Professionalism in the early childhood workforce in England', Contemporary Issues in Early Childhood 14(3), 212-222.

Corr, L., LaMontagne, A.D., Cook, K., Waters, E. \& Davis, E., 2015, 'Associations between Australian early childhood educators' mental health and working conditions: A Cross-sectional study', Australasian Journal of Early Childhood, 40(3), 69-78.

Emery, D.W. \& Vandenberg, B., 2010, 'Special education teacher burnout and ACT', International Journal of Special Education 25(3), 119-131.

Estola, E., Erkkilä, R. \& Syrjälä, L., 2003, 'A moral voice of vocation in teachers' narratives', Teachers and Teaching: Theory and Practice 9(3), 239-256.

Fernet, C., Guay, F., Senécal, C. \& Austin, S., 2012, 'Predicting intraindividual changes in teacher burnout: The role of perceived school environment and motivational factors', Teaching and Teacher Education 28, 514-525.

Gewirtz, S., Mahony, P., Hextall, I. \& Cribb, A. (eds.), 2009, Changing teacher professionalism: International trends, challenges and ways forward, Routledge, Oxon.

Hakanen, J., 2009, Työn imua, tuottavuutta ja kukoistavia työpaikkoja? Koht laadukasta työelämää [Work engagement, productivity, and flourishing workplaces? Towards high-quality working life]. Report of the Finnish Institute of Occupational Health, Helsinki.

Hall-Kenyon, K.M., Bullough, R.V., MacKay, K.L. \& Marshall, E.E., 2014, 'Preschoo teacher wellbeing: A review of the literature', Early Childhood Education Journal 42(3), 153.

Hanson, M.J., Horn, E., Beckman, P., Morgan, M., Marquart, J., Barnwell, D. \& Chou, H.-Y., 2001, 'After preschool inclusion: Children's educational pathways over the early school years', Exceptional Children 68(1), 65-83.

Heckman, J., 2014, 'Going forward wisely', Paper presented at the The White House Summit on Early Education, Washington, DC, viewed on 15 December 2014, from http:// heckmanequation.org/content/white-house-summit-early-education\#disqus_thread

Fagley \& Adler, 2012.

Kaga, Y., Bennett, J. \& Moss, P., 2010, Caring and learning together. A cross-national study on the integration of early childhood care and education within education, UNESCO, Paris, pp. 141

McManus, B.M., Carle, A.C. \& Rapport, M.J., 2014, 'Classifying infants and toddlers with developmental vulnerability: Who is most likely to receive early intervention?', Child: Care, Health and Development 40(2), 205-214.

Nilholm, C., Almqvist, L., Göransson, K. \& Lindqvist, G., 2013, 'Is it possible to get away from disability based classifications' in education? An empirical investigation of the Swedish system', Scandinavian Journal of Disability Research 15(4), 379-391.

Nislin, M.A., Sajaniemi, N., Suhonen, E., Sims, M., Hotulainen, R., Hyttinen, S. \& Hirvonen, A., 2015a, 'Work demands and resources, stress regulation and quality of pedagogical work among professionals in Finnish early childhood education settings', Journal of Early Childhood Education Research 4(1), 42-67.

Nislin, M.A., Sajaniemi, N.K., Sims, M., Suhonen, E., Maldonado Montero, E.F., Hirvonen, A. \& Hyttinen, S., 2015b, 'Pedagogical work, stress regulation and workrelated well-being among early childhood professionals in integrated special dayrelated well-being among early childhood professionals in integrated
care groups', European Journal of Special Needs Education 31, 27-43.

Nummenmaa, A.R. \& Karila, K., 2006, 'Collaborative planning in a multi-professional day-care center - PBL as a strategy and script for learning', in E. Poikela \& A.R. Nummenmaa (eds.), Understanding problem based learning, Tampere University Press, Tampere, p. 221.

Onnismaa, E.L. \& Kalliala, M., 2010, 'Finnish ECEC policy: Interpretations, implementations and implications', Early Years 30(3), 267-277.

Osgood, J., 2006, 'Deconstructing professionalism in early childhood education: Resisting the regulatory gaze', Contemporary Issues in Early Childhood 7(1), 5-14.

Paju, B., Räty, L., Pirttimaa, R. \& Kontu, E., 2015, 'The school staff's perception of their ability to teach special educational needs pupils in inclusive settings in Finland' International Journal of Inclusive Education 1-15.

Park, S., Yang, S. \& Sims, M., 2015, 'Child care teachers' attitudes toward the integration of care and education in Korea', Australasian Journal of Early Childhood.

Perhoniemi \& Hakanen, 2013.

Pihlaja, P., 2009, 'Erityisen tuen käytännöt varhaiskasvatuksessa - näkökulmana inkluusio [Special education practices in early childhood education from a perceptive of inclusion]', Kasvatus 2, 146-156.

Rantala, T. \& Määttä, K., 2011, 'Ten thesis of the joy of learning at primary schools', Early Child Development and Care 182, 87-105. http://dx.doi.org/10.1090/0300 4430.2010 .545124

Roffey, S., 2012, 'Pupil well-being - Teacher well-being: Two sides of the same coin?', Educational \& Child Psychology 29(4), 8-17.

Sachs, J., 2001, 'Teacher professional identity: Competing discourses, competing outcomes', Journal of Education Policy 16(2), 149-161.

Schaufeli, W.B., Bakker, A.B. \& Van Rhenen, W., 2009, 'How changes in job demands and resources predict burnout, work engagement, and sickness absenteeism' Journal of Organizational Behavior 30, 893-917.

Schaufeli, W.B. \& Bakker, A.B., 2014

Sims, M., 2013, 'The importance of early years education', in D. Pendergast \& S. Garvis (eds.), Teaching early years: Curriculum, pedagogy and assessment, Allen and Unwin, Crows Nest, NSW, pp. 20-32. 
Sims, M., 2014, 'Is the care-education dichotomy behind us? Should it be?', Australasian Journal of Early Childhood 39(4), 3-11.

Sims, M., Forrest, R., Semann, A. \& Slattery, C., 2015, 'Conceptions of early childhood leadership: Driving new professionalism?', International Journal of Leadership in Education: Theory and Practice 18, 149-166. http://dx.doi.org/10.1080/136031 24.2014.962101

Sims, M. \& Pedey, K., 2015, 'Are we all travelling similar paths to early childhood professionalisation? The case of Bhutan', International Journal of Innovation and Research in Educational Sciences 2(3), 218-226.

Sims, M. \& Tausere-Tiko, L., in review, 'We're going on a bear hunt: Reconciling neoliberalism and postcolonialism in Pacific early childhood', Paper submitted to Cogent Education, 19 October 2015.

Sims, M. \& Waniganayake, M., 2015a, 'The performance of compliance in early childhood: Neoliberalism and nice ladies', Global Studies in Early Childhood 5(3), 333-345. http://dx.doi.org/10.1177/2043610615597154
Sims, M. \& Waniganayake, M., 2015b, 'The role of staff in quality improvement in early childhood', Journal of Education and Training Studies 3(5), 187-194. http:// dx.doi.org/10.11114/jets.v3i5.942

Sylva, K., Melhuish, E., Sammons, P., Siraj-Blatchford, I. \& Taggart, B. (eds.), 2010, Early childhood matters: Evidence from the effective pre-school and primary education project, Routledge, London.

Suhonen \& Nislin, 2012.

Thorpe, K., Boyd, W. \& Brownlee, J., 2011, 'Who wants to work in child care? Preservice early childhood teachers' consideration of work in the childcare sector', Australasian Journal of Early Childhood 36(1), 85-94.

Trede, F., 2012, 'Role of work-integrated learning in developing professionalism and professional identity', Asia-Pacific Journal of Cooperative Education 13(3), 159-167.

Vandell, D.L. \& Wolfe, B., 2000, Child care quality: Does it matter and does it need to be improved? Special Report No. 78, Institute of Research on Poverty. 